\title{
Needs-Based Assessment of Instructional Materials in the Kindergarten Level: A Husserlian Phenomenology Study
}

\author{
Kathy N. Garcia, LPT ${ }^{1}$, Ma. Christina A. Gallaza, MA.Ed ${ }^{2}$, \\ Las Johansen B. Caluza, Ph.D. ${ }^{3}$ \\ 1 kathy.garcia@lnu.edu.ph \\ ${ }^{1}$ College of Education, Leyte Normal University, Tacloban City, 6500, Philippines \\ 2 machristina.gallaza@lnu.edu.ph \\ ${ }^{2}$ College of Education, Leyte Normal University, Tacloban City, 6500, Philippines \\ 3 lasjohansencaluza@lnu.edu.ph \\ ${ }^{3}$ College of Arts and Sciences, Leyte Normal University, Tacloban City, 6500, Philippines
}

\begin{abstract}
Instructional materials come in various shapes and sizes, but they share one thing in common: the potential to help student learning. The prevailing purpose of this study is to seek the insights of the classroom teachers on the available instructional materials used in teaching Kindergarten in a certain public elementary school in Tacloban City Division and the participants will be selected through purposive sampling. This study is supported by the Meaningful Reception Learning Theory of David Ausubel which states that teachers or instructional designers can best arrange the conditions that facilitate learning for students. This study utilized the Husserlian phenomenological design using Colaizzi's descriptive phenomenological method of data analysis through semistructured interviews. The result of this study could provide insights on the available instructional materials in a Kindergarten classroom and what other materials could be produced to aid in the teaching process.
\end{abstract}

Keywords: Education, Instructional materials, Phenomenology, Colaizzi's descriptive phenomenological method, Learning Theory, Leyte, Philippines

\section{Introduction}

Instructional materials have proven its vital role in the teaching and learning process as it enhances the memory level of the students. Now that education has spread widely and entirely, oral teaching cannot be the key to successful pedagogy; thus, the teacher must use learning materials to make teaching and learning interesting (Hulls,2003; Raw 2006). According to Abdullah (2010), training materials are instruments made or imported locally that help promote the teaching-learning process. Obanga (2005) views them as material things that are used to compose ported that could make significant enhancement of intellectual use to the students.

The use of educational materials will cater to individual attention by establishing an interesting target that will help the learner to make a direct effort. The teacher's problem of motivation is essentially one of arranging situations with which instructional materials could address.

Brown, et.al (2005) summarized the function of educational materials as follows:

- Promotes meaningful collaboration and successful learning.

- $\quad$ They ensure retention, making learning more lasting.

- $\quad$ They help overcome the restricted classroom by making the inaccessible visible.

- A common experience in which late learning can be developed is provided. It encourages and empowers learners to participate in and understand.

- Participation is encouraged, particularly, if students are allowed to control the materials used.

The Department of Education and its related collaborators are responding to a major and profound need to change the nature of essential education in the Philippines through a comprehensive educational reform known as the $\mathrm{K}$ to 12 program. $\mathrm{K}$ to 12 covers a mandatory kindergarten and 12 years of formal education (six (6) years of elementary education, four (4) years of junior high school, and two (2) years of senior high school). 
This launch of what is probably the most comprehensive basic education reform initiative ever undertaken in the country since the establishment of the public education system more than a century ago. The challenges are great especially on the instructional materials and aids to be utilized in the teaching-learning process that will conform to the standards set by this new reform agenda.

It is the goal of every teacher in the field to deliver quality education with the aid of relevant, appropriate, and contextualized instructional materials. Hence, it is but necessary to conduct a needs-based assessment to the school understudy to help in providing instructional materials that will cater to their needs.

\section{Literature Review}

Every teacher needs supplies to provide a better classroom. Teachers use a variety of tools to foster learning, and one of which is the use of Instructional Materials. Instructional materials are the resources that teachers use to deliver instruction, improve and promote teaching and learning activities. They are materials used in the instruction process. They are also resources that organize and support instruction such as textbooks, lectures, readings, and multimedia components. Any resources that teachers use to help him teach his students are an example of instructional material.

According to Akkinson, the use of resources is more effective than phrases or verbalization. This can only be done through training materials that represent real-life situations. This is how they can communicate the desired meaning to the receiver as they have received it, to appreciate and adapt the knowledge acquired to real-life circumstances. Instructional materials are educative materials that make learning and teaching possible (Obanya, 2001). Abdullahi (2003) IM's views are products or tools made or imported locally that, if used intelligently, will make an immense difference in the lesson. According to Judy (2001), learners add to what they have learned in the early explorations as learners expand during the preschool and kindergarten years. The environment plays a critical role, the richer the environment the more concrete the opportunities there are for learners to learn by interacting with Instructional Materials. IM's are tools used for the teaching and learning process. It supports the teacher in the delivery of knowledge or helps emphasize specific knowledge. Concerning this, Thungu (2008) also stated that IMs meet the needs of learners fulfill the requirements of the subjects, and facilitate the teaching and learning process.

According to Piaget (2009) instructional materials main function as a communication device is to deliver a more tangible reference to meaning than a spoken or written text. In fact, "one remembers only $10 \%$ of what is heard and $90 \%$ of what is heard, seen, and done" explained Bonska. Berry and Buktenica stated that instructional materials are very important in education. This was also attributed to the fact that audiovisual products had an enormous impact on the receiver. Furthermore, merely using IM does not guarantee effective teaching, to make teaching and participation effective the IM must be appropriately selected and used (Piaget, 2009). Mwangi (2010) pointed out that IM serves to enhance retention, making learning more permanent in the teaching-learning process. They stimulate and sustain an interest in learning by providing the first-hand experience of both the realities of the social and physical environment.

Materials for preschoolers and kindergarteners should support their developing social skills and interest in adult roles, growing imaginations, increasing motor skills, and rapidly expanding vocabularies (Jalongo \& Bacon, 2010). Getting your hands on valuable teaching materials is not nearly as difficult as it seems at first. The Internet provides many tools for teachers, most of which are free and can greatly increase the content of your teaching toolbox. You can also make your materials. Any learning material you create would be an advantage to you when you teach a related unit next. Investing time and money in good teaching materials is an expenditure in good teaching. According to Phyllis (2011), teaching materials have certain inherent benefits that make them special in teaching. They offer an interesting and convincing forum for the instructor to express knowledge as they inspire learners to continue to learn more and more. In addition, by offering 10 opportunities for private research and comparison, the enthusiasm and curiosity of the learner are gradually stimulated. Also, the instructor is aided in addressing physical challenges that may have hampered the successful presentation of the lesson. In general, they make teaching and learning simpler and less frustrating. They are similarly indispensable catalysts for the social and academic growth of learners. In carrying out the essential role of teaching materials on learning, Bouska also advised that because resourcefulness is the basic quality of a good life, teaching practices in the classroom should entail more resourceful issues. Thus, the role of audiovisual materials on the development of social awareness is more powerful than words alone if they are linked to the learning process. 
This is because it is known that others learn more as they hear and see, while some learn more about the sense of listening, touching, sensing, and obtaining knowledge. This may also confirm that "what we hear we forget, what we see we tend to remember, and what we see and hear we remember more."

As a result, for proper dialogue and interpretation of social ideas, teaching materials are most frequently used to drive home the idea, particularly to a non-literate audience. Thus, the use of learning materials plays an important role because they work more efficiently and are used to supplement textbooks.

It is widely said and accepted that the only way to support learners is to put them face to face with educational methods.

\section{Research Problem}

The study aims to address the following research questions:

1. What are the available instructional materials in the Kindergarten classroom at present?

2. What are the challenges of the Kindergarten teacher in terms of instructional materials design, development, implementation, and evaluation?

\section{Theoretical Framework}

The theoretical underpinning of this research was based on David Ausubel's (1966) Meaningful Reception Learning Theory. This theory has had a major curricular influence, especially on instructional designers. It is primarily concerned with how students learn vast volumes of substantive content from oral or written explanations in a school environment. He emphasizes that meaningful learning results when new information is acquired by linking the new information in the learner's cognitive structure.

The use of advanced organizers is the main teaching mechanism suggested by Ausubel. Ausubel points out that advance organizers are independent overviews and summaries that specifically emphasize main topics and are presented at the same level of abstraction and generality as the rest of the text. Organizers are helping to connect new learning materials to current similar concepts. The concepts of Ausubel's Meaningful Reception Learning Theory within a classroom environment include: (1) First, the more basic ideas of the subject should be introduced and then increasingly distinguished in terms of detail and precision. (2) Educational materials should aim to integrate current content with previously provided knowledge through contrasts and cross-references of new and old concepts. (3) Teachers should incorporate advance organizers when teaching a new concept. (4) Teachers should use a variety of scenarios to concentrate on similarities and disparities. (5) The use of the philosophy of Ausubel in the classroom can avoid rote learning of materials that can be studied more meaningfully. (6) What the learner already learns is the most important single element that affects learning.

\section{Methodology}

\subsection{Research Design}

Husserlian Phenomenology design was used in this study to explore and described materials and challenges experienced by the participants in a public elementary school in Tacloban City Division. Husserlian Phenomenology is also known as Descriptive Phenomenology, and has been used to reach true definitions by interacting profoundly in reality (Laverty, 2003; Lopez \& Willis, 2004). Husserl valued the perception of a phenomenon as viewed by human consciousness as an object of empirical study (Lopez \& Willis, 2004).

\subsection{Research Methods}

In the conduct of the study, the researchers sought the approval of the Schools Division Superintendent of Tacloban City Division. The researchers were provided with the result of the most recent National Achievement Test as the basis for determining the elementary schools that participated in the study. Upon identifying the schools, the principals were contacted and a consent form to voluntarily participate in this study was signed by the principal/school head and the teacher concerned. One-on-one interviews were performed using the researcher's semi-structured interview guide. The interview was recorded using a cellular phone recorder. 
The following school and teacher selection criteria were used to purposively identify the participant of this study.

\section{a. School Selection Criteria:}

The identified school is a public elementary school implementing the $\mathrm{K}$ to 12 curricula. It must also be one of the low-performing schools in Tacloban City based on the National Achievement Test for School Year 2016-2017.

\section{b. $\quad$ Teacher Selection Criteria}

The teacher must be handling Kindergarten level for the school year the study was conducted.

\subsection{Data Analysis}

Colaizzi's (1978)'s distinctive seven-step method offers a thorough analysis, with each step remaining close to the results. The result is a concise and detailed overview of the phenomena under study, verified by the participants who created it (Morrow, Rodriguez, \& King, 2015). The stages are outlined below:

\section{Table 1. Steps in Colaizzi's descriptive phenomenological method}

\begin{tabular}{|cl|l|}
\hline Step & Description \\
\hline 1. & $\begin{array}{l}\text { Familiarization of the } \\
\text { data }\end{array}$ & $\begin{array}{l}\text { The researchers familiarize or themselves with the data, by reading } \\
\text { through all the participant accounts several times. }\end{array}$ \\
\hline 2. & $\begin{array}{l}\text { Identifying significant } \\
\text { statements }\end{array}$ & $\begin{array}{l}\text { The researchers must classify all claims in the accounts that are of } \\
\text { particular significance to the phenomena under investigation. }\end{array}$ \\
\hline 3. & Formulating meanings & $\begin{array}{l}\text { The researchers identify meanings relevant to the phenomenon that arise } \\
\text { from a careful consideration of the significant statements. }\end{array}$ \\
\hline 4. & Clustering themes & $\begin{array}{l}\text { The researchers cluster the established meanings into themes that are } \\
\text { similar to all accounts. }\end{array}$ \\
\hline 5. $\begin{array}{l}\text { Developing an } \\
\text { exhaustive description }\end{array}$ & $\begin{array}{l}\text { Researchers write a complete and inclusive overview of the phenomenon, } \\
\text { including all the themes generated in Step 4. }\end{array}$ \\
\hline f. & $\begin{array}{l}\text { Producing the } \\
\text { fundamental structure }\end{array}$ & $\begin{array}{l}\text { The researchers condense the exhaustive explanation into a simple, dense } \\
\text { statement that captures only those elements that are considered essential to } \\
\text { the structure of the phenomenon. }\end{array}$ \\
\hline 7. & $\begin{array}{l}\text { Seeking verification of } \\
\text { the fundamental } \\
\text { structure }\end{array}$ & $\begin{array}{l}\text { Researchers return to all participants (or often to a sub-sample in broader } \\
\text { studies) the simple structure statement to ask if it captures their } \\
\text { experience. In the light of this input, he or she can go back and adjust } \\
\text { earlier steps in the study. }\end{array}$ \\
\hline
\end{tabular}

\subsection{Ethical Considerations}

The safety and confidentiality of the participant were carefully considered before, during, and after the study. Permission from gatekeepers or authorities such as the Schools Division Superintendent, Principal, or School Head was sought first before the conduct of school visitation and interview with the teacher. The participant signed the informed consent form before the interview. Great care was taken to ensure that no physical or emotional harm will be experienced by the participant as a direct or indirect result of her participation in the study.

\subsection{Reflexivity Statement}

The researchers and students who visited the school were reminded to be careful in dealing with every person of the school. Interview transcripts were transcribed verbatim and it was sent back to the participant for accuracy and cross-checking. 


\section{Results and Discussion}

Based on the different research procedures conducted about this study, the relevant finding was generated to extensively present the experiences of Kindergarten teachers in teaching.

\section{Theme 1: Available Instructional Materials in the Kindergarten Classroom}

\section{A. Non-printed Instructional Materials}

\section{Projected Media}

The participant reported the instructional materials she commonly used in her instruction such multimedia presentations and educational videos.

“. . . . Nagdadownload ko hin mga educational videos ha youtube kay nakikit an ko na interesado gud it mga kabataan" (p2, ln23-24)

“. . . Kun mayda mga higrayo nga lugar na gusto ko ipakita haira, nagamit ako hin powerpoint presentation ngan ginkaakdto ko an picture.” (p2, ln30-31)

There is a better understanding today than ever before as to how children learn and what kind of activities and things serve as efficient means and tools for learning. Ampa (2013) said that instructional materials in the form of pictures, slides, filmstrips, recordings when properly used can make a significant contribution to learning, reinforcing the role of textbooks, oral instruction, and exercises.

\section{Non-projected Media}

These are all visual displays that can be shown to a class, small group, or individual student without the use of an optical or electronic projector.

“... We have counters used if the lesson is on numeracy.” $(p 3, \ln 2)$

“. . . Myda kami mga manipulatives ngan mga blocks pero duro kagudti, diri advisable haira nga magamit kay bangin niruniyan kaunon.” (p3, ln15-16)

“. . . Nagagamitan gihapon namon an mga recyclable materials like an burutangan han bunay (egg tray)”. (p3, ln20)

Piaget believed that the first few years of a child's life were the most remarkable, and the academic experience of those years at or beyond the school had a predominant effect on the child's future pattern of behavior. Seeing, listening, touching, tasting, and controlling objects in the setting teach your kid what the world is like. Sensory perceptions of all sorts tend to improve and enrich the awareness of the infant. Toys, building blocks, manipulatives complement spoken or written words with tangible representations and thereby provide a rich perspective which is the foundation for learning.

\section{B. Print Media Instructional Materials}

Both text and handout materials to be used by students or trainees, which can be used in vast quantities by printing machines or photocopiers.

“. . . Pirmi ako nagamit hin pictures pag nagkaklase ako, kinahanglan ito para mas maintindihan hit bata tak leksyon." (p3, ln22-23)

“. . . May ada namon small books ngan big books na available pero gutiay la.” (p3, ln28) 
Dekker (2010) pointed out that pictures or a chart or even a simple drawing on the blackboard can provide the child an entirely new experience in understanding an idea or a concept. A visual presentation of an idea or a concept using printed materials helps the children to develop mental images of the object.

Seeing and listening together can be more compelling and efficient than just hearing. Data indicates that $80 \%$ of learning happens when the idea is seen and understood, and therefore print media help to enhance learning and teaching.

\section{Electronic Instructional Materials}

\section{Audio}

All devices where straightforward audio content can be played to a class, group, or person. Sound plays such an important role in the learning process that a significant number of sound instruments have been developed as a result of the advancement of technology in education, Valdez (2012). During the interview, it was mentioned by the participant that audio devices such as speakers and cd players are often used in the Character Formation and Motor Skills subjects.

\section{Visual}

This is a media that allows audio signals to be paired with moving video sequences, allowing a more layer to be applied to the blended audio-visual presentation.

The participant said that she has available visual electronics materials such as a laptop and printer which she could buy at her own expense. She found it very relevant in her profession since Kindergarten learners would learn more if the concept is shown or presented to them. On the other hand, a projector is also available at their school through a reservation that is needed when the teacher wishes to use the equipment due to its limited number.

\section{Audio- Visuals}

Looking at pictures, listening to a story, watching educational videos, looking at a puppet show are some of the interesting activities that the research participant is providing to the children.

In the 1950s and 60s, developments in communication theories and system concepts led to studies of the educational process, its elements, and their interrelationships. Among these elements are the teacher, the teaching methods, the information conveyed, the materials used, the students, and the students' responses. As a result of these findings, the study of audio-visuals changed its focus from equipment and materials to the analysis of the teaching-learning process. The area is known as audiovisual communications and instructional technologies, and audiovisual materials have been viewed as an important part of the education system. Marc Prensky (2001) said that nowadays, students think and process information differently from their predecessors.

Nancy Kassebaum (2005) highlighted that there can be countless usage of computers and new-age technologies, but if the teachers themselves are unwilling to carry it into the classroom and make it functional, it will fail. 


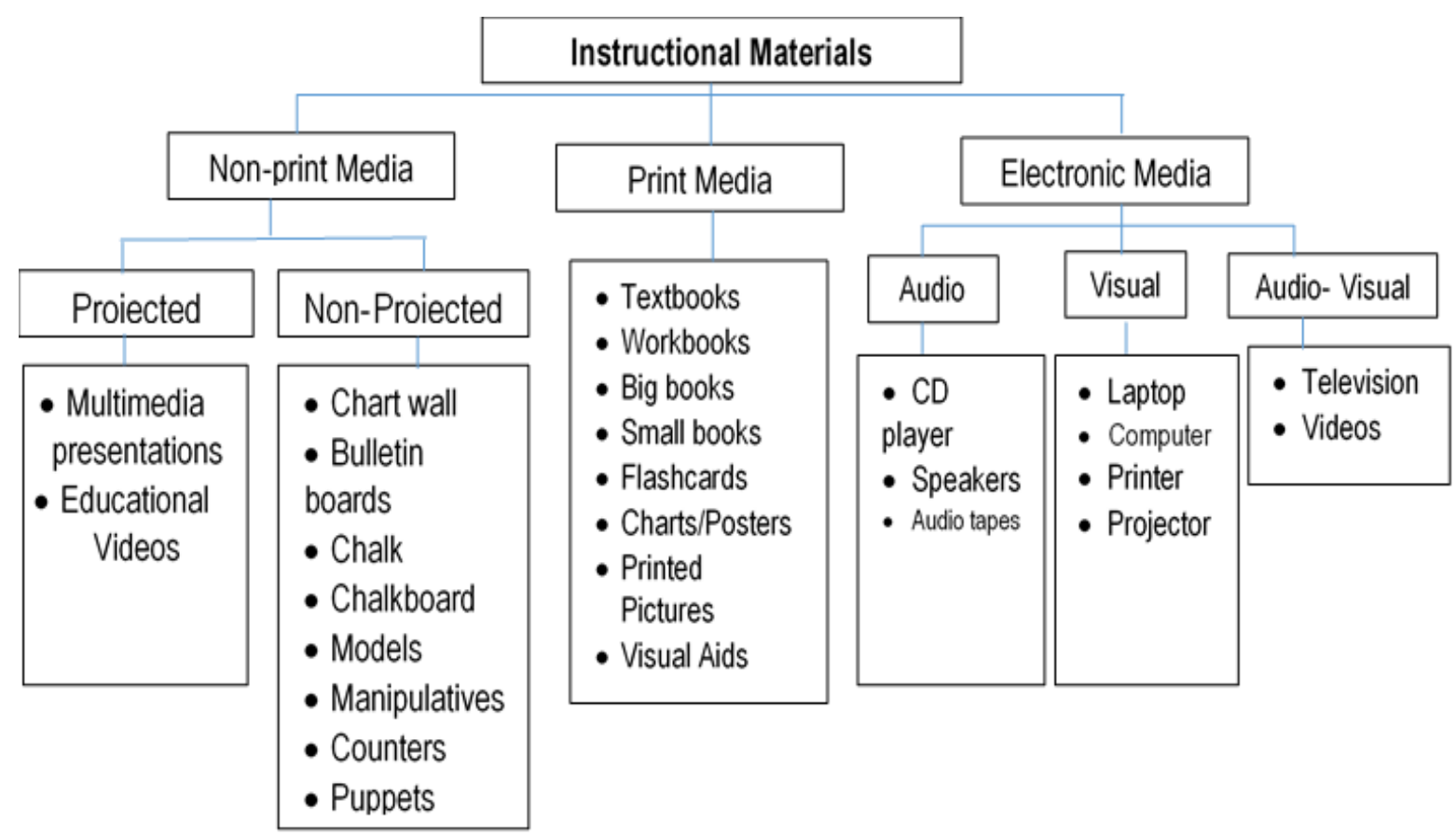

Fig. 1. Theme 1: Available Instructional Materials in the Kindergarten Classroom

\section{Theme 2: Challenges Met by the Kindergarten Teachers in terms of Instructional Materials}

\section{Insufficient Materials}

Teachers in the field often encounter problems in terms of supplies and materials needed to create instructional materials. It hinders them in producing quality and appropriate materials in teaching the content since they were left with no choice but to use whatever is available. The following are the statements of the participants that support this idea:

“. . . kulang kami hin mga materials na pwede naon magamit paghimo hin IMs asya kun ano it may ada namon asya tam gingagamit pagtutdo” ( $66, \ln 26-27)$

“. . . Actually, struggle talaga namon it music kay waray man talaga kami dinhi mga music instruments na pwede namon magamit, although mayda kami banda an available la kasi nga anu, drum and lyre la, so..." (p6, ln30-32)

“. . . An storytelling liwat mas maupay kun may puppet liwat ba kay mas naeenjoy nira pagwaynakikitan nira nga mga movement, mga character ba hiton nga story.” (p6, ln12-13)

“... Kun may numbers, mayda liwat illustration nga like one mayda liwat drawing nga one.” (p6, $\ln 31)$

“. . . Mga ano? Mas ano kasi nakakaintindi it kabataan kun may pictures tas amo lagi adto pictoword nga ig-dridrill namon ba every day, anu pa...” (p6, ln37-38)

Kalin (2004) emphasized that the sufficiency of materials is one key factor to produce quality instructional materials to be used in the teaching and learning process. It is indeed, without doubt, one of the key components for effective teaching. Hence, the sufficiency of the materials in each classroom must be properly checked and looked into by the administrators. 


\section{Lack of Contextualized Resource Materials}

With the implementation of the MTB-MLE from Kindergarten to Grade Three levels, teachers faced difficulty in producing contextualized instructional materials since not all subject matters were provided with textbooks or resource materials were already in the mother tongue language. Here are some of the responses of the participants concerning this issue:

“... waray kami, an big books waray na Winaray, medyo limited an amon... although mayda ha amon ginpapa... mayda ginhatag ha amon nga softcopy hin mga stories.” (p5, $\ln 1-2)$

“. . . i-provide pa namon para maging big books talaga hiya.” (p5, ln12)

“. . . kami pa mismo, it naghihimo ba, gin lalayout pa namon para big books tagalaga hiya gumawas." (p5, 26-27)

“. . . amo la't ira common, amo la't ira kilala, so padrawingon mo man hira hit nga musical instruments, it ira la nanunumduman amo ito hiya, so, once nga magsiring ka nga piano "Ma'am anu ito hiya nga piano?" so kailangan mo pa magprovide hin kuan.. pictures, bisan it pictures diri pa gud iton nira naiintindihan. "Papaanu iton ma'am patukaron? It ira la kasi nakikita ngada is drum ngan lyre, so amo gihap iton, makurukuri.” (p4, ln32-34)

According to Taylor (2004), to contextualize, teachers must use authentic materials and anchor teaching in the context of learners' live. Considering this, it is a big challenge for the teacher to come up with this kind of teaching material if no enough contextualized resource materials will be provided to them.

\section{Conclusion}

The study found out that there are limited instructional materials available at present in the Kindergarten classroom in this certain public elementary school in Tacloban City Division. Kindergarten teachers see the importance of contextualized instructional materials relevant in teaching the Kindergarten pupils to respond to their needs and varied learning styles. Further to make pupils apply and appreciate what they learned in the actual setting. Hence, this study guides the teachers in terms of instructional materials that need to be developed and produced appropriate for the Kindergarten classes.

This also gives a clearer direction to our school heads to give support and provide necessary training to the faculty on how to contextualize the lessons for MTB-MLE instruction. Provide workshops on instructional materials design, construction, development, implementation, and evaluation which will fit in our new modality of learning.

\section{References}

Ampa, A (2013). Developing multimedia learning materials for speaking skills based on contextual teaching and learning. Unpublished dissertation. Post Graduate Program. The University of Makassar.

Ausubel, D. P. (1966). Meaningful reception learning and the acquisition of concepts. In Analyses of concept learning (pp. 157-175). Academic press.

Colaizzi, P. (1978). Psychological research as a phenomenologist views it. In: Valle, R. S. \& King, M. (1978). Existential Phenomenological Alternatives for Psychology. Open University Press: New York.

Dekker, D. (2010). What is mother tongue-based multilingual education? Starting where the children are, 23-25.

Hulls, G. (2003). Student model designs for instruction. Educational technology research and development, 54(1),83-106. 
Kalin J. (2004). The Role of Media in Modern Lessons and the Judgement of their Efficiency. Washington, US. Department of Education.

Kassebaum, N. (2005). Instruction to technology, Johns Ltd publisher, Lagos

Laverty, S. (2003). Hermeneutic phenomenology and phenomenology: A comparison of historical and methodological considerations. International Journal of Qualitative Methods, 2(3), 1-29

Lopez, K., \& Willis, D. (2004). Descriptive versus interpretive phenomenology: Their contribution to nursing knowledge. Quality Health Research, 14, 726-735

Morrow, R., Rodriguez, A., and King, N. (2015). Colaizzi’s descriptive phenomenological method. The Psychologist, 28(8), 643-644

Obanga, M. (2005) Handbook of procedures for the design of instruction. Pittsbrurg: American Institutes for Research.

Prensky M. (2010). The use of instructional materials in teaching. (ed) in fundamental of educational technology. Unicross.

Raw, D. (2006). The role of educational technology. International Journal of Academic Research, 2(6),188-192.

Saglam, H.I. (2011). An Investigation on teaching Materials Used in Social Studies Lessons. The Turkish Online Journal of Educational Technology, 10(1), 36-44.

Sosha, L. (2012).Aids for teaching and learning: instructional materials. Ibadan, Nigeria.

Valdez, A.P. (2012). Curriculum Model for Media and Technology: Lessons from International Benchmarking. International Journal of Multidisciplinary Research, 3(1), 292-301.

Wang, F., \& Reeves, T. C. (2003). Why do teachers need to use technology in their classrooms? Issues, problems, and solutions. Computers in the Schools, 20(4), 49-65. 